\title{
Impact of Extracapsular Lymph Node Involving the Esophagus in Esophageal Perforation During and After Radiotherapy: A Propensity Score-Matched Analysis
}

This article was published in the following Dove Press journal:

Cancer Management and Research

\section{Chen Chen ${ }^{1 * *}$ \\ Xiaobin $\mathrm{Fu}^{2}$,* \\ Yaqing Dai ${ }^{3}$ \\ Qiwei Yao' \\ Liyuan Huang' \\ Jiancheng $\mathrm{Li}^{1}$}

'Department of Radiation Oncology, Fujian Cancer Hospital \& Fujian Medical University Cancer Hospital, Fuzhou, Fujian 3500 14, People's Republic of China; ${ }^{2}$ Department of Radiation Oncology, The Second Affiliated Hospital of Fujian Medical University, Quanzhou, Fujian 362000, People's Republic of China; ${ }^{3}$ The Department of Radiation Oncology, The First Affiliated Hospital of Xiamen University, Xiamen, Fujian 361003, People's Republic of China

*These authors contributed equally to this work
Correspondence: Jiancheng Li Department of Radiation Oncology, Fujian Cancer Hospital \& Fujian Medical University Cancer Hospital, Jin'an

District, Fuzhou, Fujian 3500I4, People's

Republic of China

Tel +86 13906900190

Email jianchengli_jack@I26.com
Background: This study aimed to analyze the risk factors for esophageal squamous cell carcinoma (ESCC), especially extracapsular lymph node involving the esophagus (ECLNIE), occurring during or after radiotherapy (RT) in patients with esophageal perforation (EP).

Methods: In total, 306 patients with ESCC who received RT and/or chemotherapy between January 2016 and December 2017 in our hospital and who met the inclusion criteria of the study were recruited. The continuous variables were converted into classification variables using the receiver operating characteristic curve or common clinical parameters. Risk factors for EP were examined by univariable analysis using the chi-square test or Fisher's exact and by multivariable analysis using logistic regression model. Propensity score matching (PSM) was used to compensate for the differences in baseline characteristics, and the incidence of EP was compared after matching.

Results: EP was observed in 26 patients (incidence rate, $8.5 \%$ ). Univariable analysis revealed that age, BMI, T4 stage, tumor length, esophageal wall thickness, ECLNIE, necrotic areas, niche sign by esophagogram before RT, neutrophil-to-lymphocyte ratio, and prognostic nutritional index were significantly associated with EP among patients with ESCC who received radiotherapy. Multivariable analysis demonstrated that age, ECLNIE, esophageal wall thickness, and niche sign by esophagogram before RT were independent risk factors for EP. After PSM, compared with patients without ECLNIE, patients with ESCC and ECLNIE had a significantly higher risk of EP.

Conclusion: The presence of ECLNIE could be a strong risk factor of EP during and after RT. Keywords: esophageal perforation, esophageal squamous cell carcinoma, propensity scorematched analysis

\section{Background}

Esophageal cancer (EC) is a common cancer and remains an integral cause of cancer-related deaths worldwide. Esophageal squamous cell carcinoma (ESCC) is the predominant subtype of EC in Asia and Africa, accounting for approximately $90 \%$ cases. ${ }^{1}$ Curative surgical therapy is the main treatment for cases of localized EC. However, in up to $75 \%$ cases, EC is too advanced for curative surgical therapy at the initial diagnosis. ${ }^{1}$ For such advanced regional and distant metastases cases, chemoradiotherapy is recommended in the National Comprehensive Cancer Network guideline and performed in clinical practice. ${ }^{2}$ 
Esophageal perforation (EP) is a severe and lifethreatening side effect during and after esophageal RT. Some studies revealed that the imbalance of tumor regression and normal tissue repair is the main cause of EP. ${ }^{3}$ Despite a $5-10 \%$ incidence rate of $\mathrm{EP}$, it is associated with a poor prognosis and a high mortality rate. ${ }^{4,5}$ In this case, the risk factors that accurately predict EP before treatment play a crucial role in the selection of optimal treatment for ESCC. Some studies ${ }^{6-8}$ demonstrated that nutritional status, T stage, extracapsular lymph nodes involving the esophagus (ECLNIE), etc. are independent prognostic factors of EP.

However, the abovementioned studies about the risk factors of EP were mainly single-center retrospective studies and have not yet reached a consensus. Moreover, the baseline characteristics in those studies were not well balanced and comparable. Therefore, we aimed to analyze the risk factors for patients with EP occurring during or after radiotherapy for ESCC and performed propensity score-matched (PSM) analysis to balance the baseline characteristics and adjust for indication biases for assessing the impact of ECLNIE.

\section{Methods}

\section{Patients}

This study was approved by the Ethics Committee of Fujian Provincial Tumor hospital. Written informed consents were obtained from all participants before treatment, and all the information was anonymized before analysis. In total, 306 consecutive patients with ESCC between January 2016 and December 2017 criteria were recruited in the study. Patients with Karnofsky score $\geq 70$ points, those with cytologically and histologically confirmed ESCC, those who had undergone treatment with intensity-modulated radiation therapy (IMRT) and/or platinum-based chemotherapy, those who had undergone thoracic CT scan and barium radiography 1 week prior to RT, to exclude those with EP, those without a history of malignant disease or serious internal diseases, and those in whom the cTNM stage was re-determined according to the 8th American Joint Committee on Cancer TNM staging system ${ }^{9}$ based on the clinical data were included. Patients who had undergone esophagectomy were excluded.

\section{Radiotherapy and Chemotherapy}

In this study, 306 patients with ESCC received IMRT for esophageal tumors. The thoracic and abdominal parts were fixed using one vacuum pad. Imaging data were collected from computed tomography (CT) simulation scan and transmitted to a radiation therapy treatment planning system (Pinnacle; version 9.2, Philips Radiation Oncology System, Wisconsin, USA) to delineate the gross tumor volume, clinical tumor volume, and the organs at risk by an experienced radiation oncologist according to the criteria of tumor delineation of the National Comprehensive Cancer Network. Radiation was delivered using a medical linear accelerator (Trilogy; Varian Medical Systems, USA) at a dose of 1.8-2.3 Gy per fraction per day, 5 days a week. The chemotherapy regimen based on cisplatin was used. It included TP (paclitaxel $135 \mathrm{mg} / \mathrm{m}^{2} \mathrm{dL}+$ cisplatin $25 \mathrm{mg} / \mathrm{m}^{2} \mathrm{dL}^{3}$ ) and $\mathrm{DP}$ (docetaxel $75 \mathrm{mg} / \mathrm{m}^{2} \mathrm{dL}+$ cisplatin $25 \mathrm{mg} / \mathrm{m}^{2} \mathrm{dL}^{3}$ ). Carboplatin was used in case of intolerance to cisplatin.

\section{Assessment of EP, ECLNIE, Niche Sign, and Necrotic Areas}

EP was assessed according to the following image manifestations observed on CT: a) gas in the mediastinum or the soft tissue of the mediastinum surrounding the esophagus; b) abscess cavity adjacent to the esophageal wall in the mediastinum or pleural space or; c) actual communication of the esophagus and the air-fluid collection in the adjacent mediastinum. ${ }^{10,11}$ EP was also assessed by leakage on iodine oil radiography.

ECLNIE was assessed based on the following image manifestations on the contrast-enhanced CT scan: extracapsular lymph node involvement in the esophageal wall deemed positive for the metastatic lymph node with irregular nodal boundaries, thickening of adjacent fascia, and apparent invasion of the esophagus tissue with or without adjacent organs ${ }^{12,13}$ (Figure 1A and B). The image was reevaluated independently by two experienced image specialists in Fujian provincial tumor hospital. The image specialists were highly trained. The interobserver variability occurred, the image was transferred to the third image specialist for independently re-evaluating.

Niche sign was assessed based on the esophageal wall outline coating with barium or iodine oil. ${ }^{14}$ Necrotic area was assessed according to the low-density area of the tumor lesion in enhanced CT scan. ${ }^{10}$

\section{Definitions of Nutrition-Based and Inflammation-Based Indicators}

The body mass index (BMI) was calculated as the body weight divided by the square of the body height. The prognostic nutritional index (PNI) was calculated by the serum 

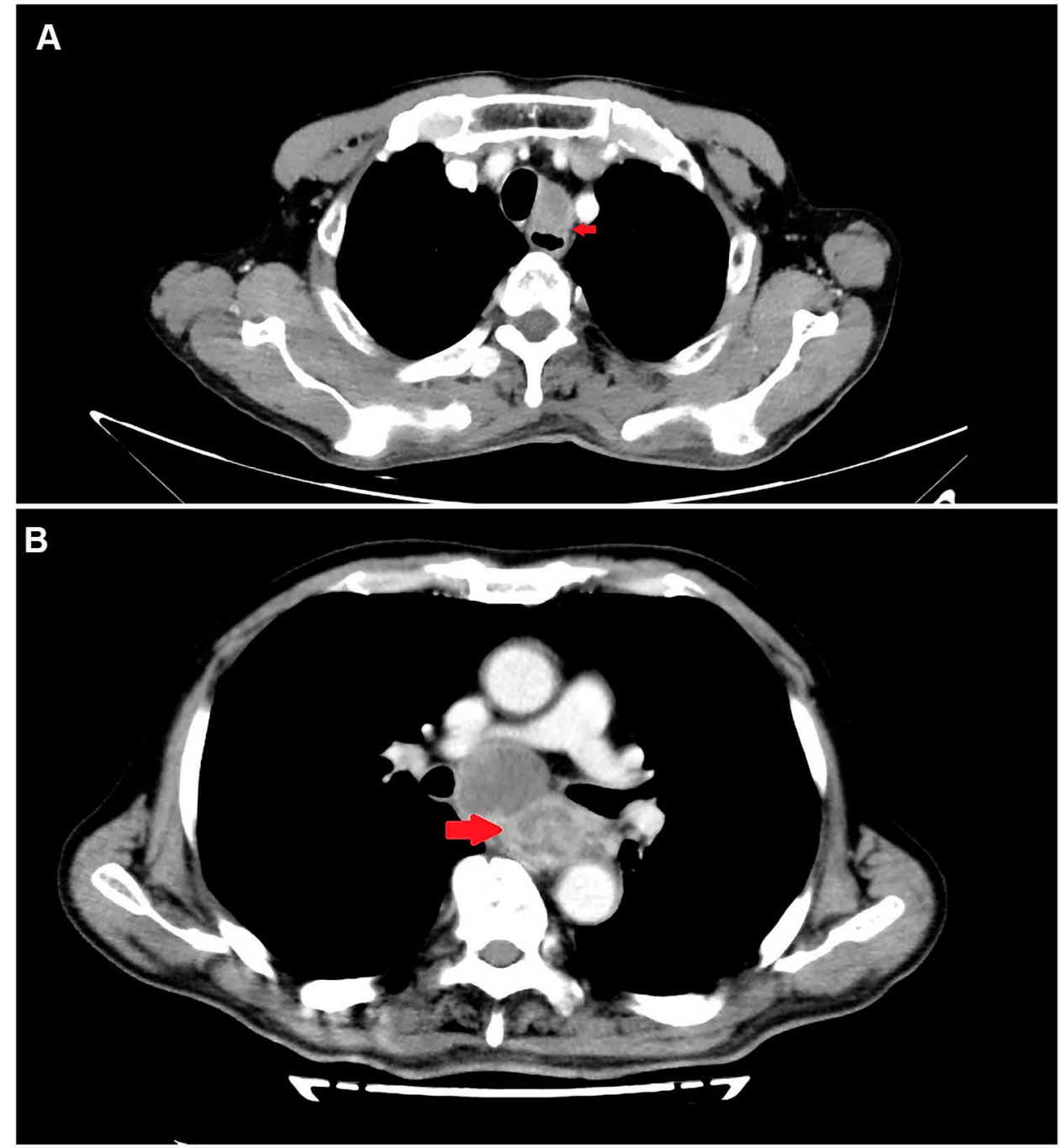

Figure I The contrast-enhanced CT scan shows extracapsular lymph node involvement in the esophageal wall deemed positive. The red arrows respectively show the extracapsular lymph node involved the normal esophagus (A) and esophageal carcinoma wall (B).

albumin level $+5 *$ absolute lymphocyte count. The neutrophilto-lymphocyte ratio (NLR) was calculated by dividing the absolute neutrophil count by the absolute lymphocyte count.

\section{Methods and Parameters of CT Scanning}

A Brilliance 256-slice spiral CT scanner (PHILIPS, Eindhoven, The Netherlands) was used for scanning, with the patient in the supine position with both arms above the head and using the following parameters: tube voltage $120 \mathrm{kV}$, tube current $300-350 \mathrm{~mA}$, scanning collimator $1 \mathrm{~mm}$, pitch 0.9 , scanning layer thickness $5 \mathrm{~mm}$, layer spacing $5 \mathrm{~mm}$, reconstruction layer thickness $2.5 \mathrm{~mm}$, and layer spacing $2 \mathrm{~mm}$. The enhanced scanning used one high-pressure syringe to rapidly inject $100 \mathrm{~mL}$ of non-ionic contrast agent (iodohydrin) from the elbow vein (injection rate $3 \mathrm{~mL} / \mathrm{s}$ ). The scanning area started from the skull base to the fifth lumbar spine, the data of which were then transmitted into Vitrea 2 Workstation for multiwindow and multiplanar reconstruction. Two experienced radiologists in our hospital retrospectively evaluated the pretreatment thoracic CT scans. The diameter of the thickest part of the primary tumor on the CT scan image was identified as the esophageal thickness. Asymmetric luminal involvement on the CT scan image was identified as the eccentric wall thickness.

\section{Surveillance and Statistical Analysis}

All patients who agreed to participate in the study underwent regular follow-up imaging examinations including CT scan, and barium radiography or iodine oil radiography before radiotherapy, every 2 weeks during radiotherapy, as well as 1 and 3 months after radiotherapy. Patients with 
severe chest pain, fever, and cough were required to undergo immediate iodine oil radiography and thoracic CT scan. The study endpoint was the incidence of EP within 6 months of RT.

All recorded data were analyzed using SPSS (version 23.0, SPSS Inc., Chicago, IL, USA) and R (version 3.2.2). The continuous variables were converted into classification variables using the receiver operating characteristic (ROC) curve or clinical common parameters. The maximal Jordan index (sensitivity + specificity -1 ) was used to determine the continuous variables in order to determine the optimal value for predicting EP. The Chi-square test or Fisher's exact test was used for univariable analysis. The clinical characteristics for univariable analysis were sex, age, BMI, smoking history, alcoholism history subclass, $\mathrm{T}$ stage, $\mathrm{N}$ stage, $\mathrm{M}$ stage, whether patients received chemotherapy, whether they received RT for the second time, tumor length, esophageal thickness, ECLNIE, eccentric wall thickness, necrotic area, niche sign by esophagogram before RT, NLR, and PNI. The variables that achieved statistical significance in the univariate analysis were entered into the multivariable analysis, which was performed using the binary logistic regression analysis (a logistic regression model). The odds ratio (OR) value and the corresponding 95\% confidence interval (CI) were calculated using binary logistic analysis to evaluate the independent risk factors for PE. A P value $<0.05$ was considered statistically significant.

PSM analysis was used to compensate for the differences in baseline characteristics between the ECLNIE and NonECLNIE groups to confirm the risk of EP difference. First, all available patient and tumor variables were compared using the Chi-square test. Next, a propensity score was calculated using logistic regression with the imbalanced variables that were statistically significantly correlated with the incidence of EP on multivariable analysis. Finally, all analyses regarding the incidence of EP adjusted based on the generated propensity score were subsequently performed to compare the differences between the ECLNIE and NonECLNIE groups after matching. Caliper matching was performed on the propensity score (nearest available matching) by the minimal adjacent method of 1:1 pairing.

\section{Results}

\section{Patient Characteristics}

A total of 306 patients ( 232 men and 74 women) who met the inclusion criteria were enrolled (Table 1). EP was observed in 26 patients, with an incidence rate of $8.5 \%$. EP occurred
Table I Patients' Characteristics for 306 ESCC Patients

\begin{tabular}{|c|c|}
\hline Characteristics & Number of Patients (\%) \\
\hline \multicolumn{2}{|l|}{ Gender } \\
\hline Male & $232(75.8)$ \\
\hline Female & $74(24.2)$ \\
\hline \multicolumn{2}{|l|}{ Age } \\
\hline$<65$ & $|5|(49.3)$ \\
\hline$\geq 65$ & $155(50.7)$ \\
\hline \multicolumn{2}{|l|}{ BMI } \\
\hline$<20$ & $98(32)$ \\
\hline$\geq 20$ & $208(68)$ \\
\hline \multicolumn{2}{|l|}{ Smoking history } \\
\hline Yes & $188(6 \mid .4)$ \\
\hline No & $118(38.6)$ \\
\hline \multicolumn{2}{|l|}{ Alcoholism history } \\
\hline Yes & $66(21.6)$ \\
\hline No & $240(78.4)$ \\
\hline \multicolumn{2}{|l|}{ T stage } \\
\hline $\mathrm{TI}$ & $4(5.9)$ \\
\hline $\mathrm{T} 2$ & $18(5.9)$ \\
\hline T3 & 105 \\
\hline $\mathrm{T} 4$ & $179(58.5)$ \\
\hline \multicolumn{2}{|l|}{$\mathbf{N}$ stage } \\
\hline No & $81(26.5)$ \\
\hline NI & $155(50.7)$ \\
\hline N2 & $57(18.6)$ \\
\hline N3 & $13(4.2)$ \\
\hline \multicolumn{2}{|l|}{ M stage } \\
\hline Mo & $225(73.5)$ \\
\hline MI & $81(26.5)$ \\
\hline \multicolumn{2}{|l|}{ Esophageal perforation } \\
\hline Yes & $26(8.5)$ \\
\hline No & $280(9 \mid .5)$ \\
\hline
\end{tabular}

during radiotherapy in 14 patients, and 12 patients developed EP 1-13 weeks after completion of radiotherapy. The mean and median intervals of development of EP were 8 and 6 weeks, respectively. Of the 26 patients with EP, 8 patients had esophagotracheal fistula, whereas the remaining patients had esophagomediastinal fistula. In total, 21 patients had ECLNIE, with an incidence rate of $80.8 \%$. Of 21 patients with EP had ECLNIE, 20 had a fistula in the site of the primary lesion, and 1 patient had a fistula in the site of extracapsular lymph node involving the normal esophageal wall. The partial response and stable disease of patients with EP were evaluated according to the RECIST criteria while eliminating the possibility of EP owing to tumor progression. 


\section{Risk Factors for EP in the Entire Cohort}

The common clinical parameters, BMI and age, were dichotomized $\mathrm{BMI}<20, \geq 20$, and age $<65$ years, $\geq 65$ years in this study. The rest of the continuous variables were dichotomized using the ROC curve to calculate the optimal cut-off value that was most significantly correlated with the risk of EP difference using the AUC. For tumor length, the AUC was 0.774 (95\% CI 0.697-0.851). The optimal cutoff value was 6.45 , and the sensitivity and specificity were 0.769 and 0.707, respectively (Figure 2A). For esophageal thickness, the AUC was 0.799 (95\% CI 0.711-0.887). The optimal cutoff value was 1.75 , and the sensitivity and specificity were 0.769 and 0.729 , respectively (Figure 2B). For NLR, the AUC was 0.715 (95\% CI 0.614-0.815). The optimal cutoff value was 2.34 , and the sensitivity and specificity were 0.731 and 0.657 , respectively (Figure 2C). For PNI, the AUC was 0.693 (95\% CI 0.601-0.786). The optimal cutoff value was 47.85 , and the sensitivity and specificity were 0.532 and 0.889 , respectively (Figure 2D). According to the criteria of predictive ability, the indicators exhibited had better predictive ability toward EP.

Univariable analysis revealed that age $(\mathrm{P}=0.011), \mathrm{BMI}$ $(\mathrm{P}=0.003), \mathrm{T} 4$ stage $(\mathrm{P}=0.005)$, tumor length $(\mathrm{P}<0.001)$, esophageal wall thickness $(\mathrm{P}<0.001)$, ECLNIE $(\mathrm{P}<0.001)$, necrotic areas $(\mathrm{P}<0.001)$, niche sign by esophagogram before RT $(\mathrm{P}<0.001)$, NLR $(\mathrm{P}<0.001)$, and PNI $(\mathrm{P}<0.001)$ were significantly associated with EP among patients with ESCC who received RT (Table 2). Multivariable analysis demonstrated that age $(\mathrm{P}=0.038)$, ECLNIE $(\mathrm{P}<0.001)$, esophageal wall thickness $(\mathrm{P}=0.044)$, and niche sign by esophagogram before RT $(\mathrm{P}=0.001)$ were independent risk factors for EP in ESCC (Table 3).

\section{Impact of ECLNIE on EP with PSM}

In total, 65 pairs consisting of 130 patients each from the ECLNIE group and the non-ECLNIE group were matched
A

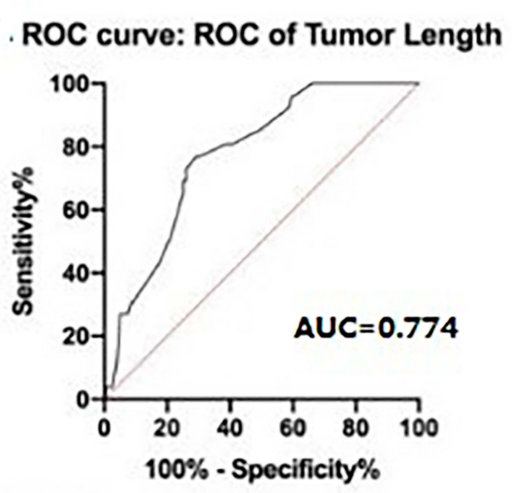

C

ROC curve: ROC of NLR

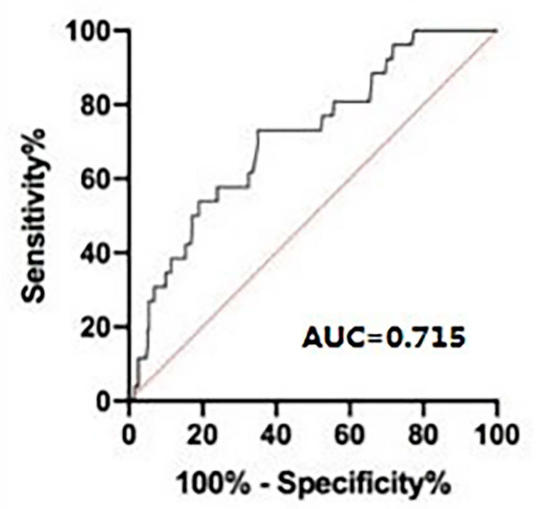

B

ROC curve: ROC of Esophageal Wall Thickness

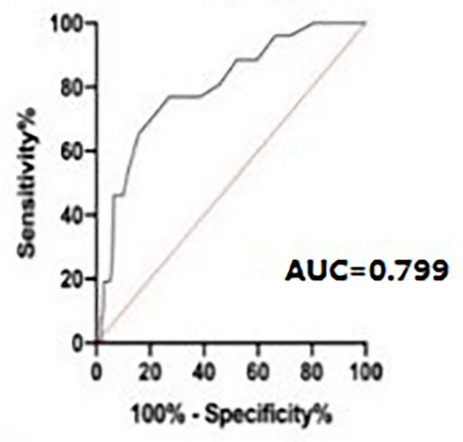

ROC curve: ROC of PNI

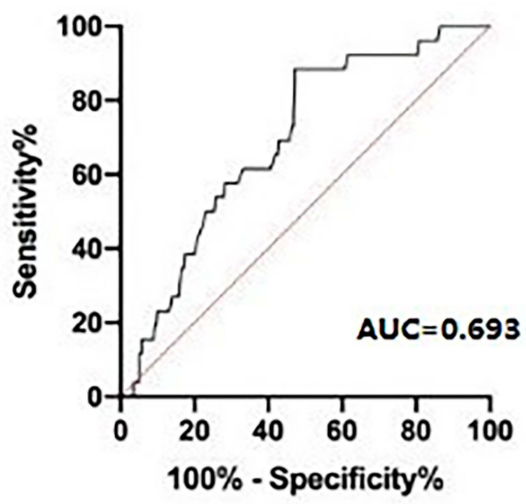

Figure 2 ROC curve of (A) tumor length, (B) esophageal wall thickness, (C) NLR, and (D) PNI for predicting esophageal perforation. 
Table 2 Univariate Analysis of 306 ESCC Patients

\begin{tabular}{|c|c|c|c|}
\hline \multirow[t]{2}{*}{ Variables } & $\begin{array}{l}\text { Non- } \\
\text { Perforation }\end{array}$ & Perforation & \multirow[t]{2}{*}{$P$ value } \\
\hline & $\mathbf{N}=\mathbf{2 8 0}$ & $N=26$ & \\
\hline \multicolumn{4}{|l|}{ Gender } \\
\hline Male & 209 & 23 & 0.115 \\
\hline Female & 71 & 3 & \\
\hline \multicolumn{4}{|l|}{ Age } \\
\hline$<65$ years old & 132 & 19 & 0.011 \\
\hline$\geq 65$ years old & 148 & 7 & \\
\hline \multicolumn{4}{|l|}{ BMI } \\
\hline$<20$ & 83 & 15 & 0.003 \\
\hline$\geq 20$ & 197 & 11 & \\
\hline \multicolumn{4}{|l|}{ Smoking history } \\
\hline Yes & $17 \mid$ & 17 & 0.666 \\
\hline No & 109 & 9 & \\
\hline \multirow{2}{*}{\multicolumn{4}{|c|}{$\begin{array}{l}\text { Alcohol consumption } \\
\text { history }\end{array}$}} \\
\hline & & & \\
\hline Yes & 61 & 5 & 0.762 \\
\hline No & 219 & 21 & \\
\hline \multicolumn{4}{|l|}{ T4 stage } \\
\hline Yes & 157 & 22 & 0.005 \\
\hline No & 123 & 4 & \\
\hline \multicolumn{4}{|l|}{ N stage } \\
\hline No & 78 & 3 & $0.07 I$ \\
\hline NI-3 & 202 & 2 & \\
\hline \multicolumn{4}{|l|}{$M$ stage } \\
\hline 0 & 208 & 17 & 0.325 \\
\hline 1 & 72 & 9 & \\
\hline \multicolumn{4}{|l|}{ Chemotherapy } \\
\hline Yes & 221 & 18 & 0.253 \\
\hline No & 59 & 8 & \\
\hline \multicolumn{4}{|l|}{$\begin{array}{l}\text { RT for the second } \\
\text { time }\end{array}$} \\
\hline Yes & 11 & 0 & 0.608 \\
\hline No & 269 & 26 & \\
\hline \multicolumn{4}{|l|}{ Tumor length } \\
\hline$\leq 6.45 \mathrm{~cm}$ & 198 & 6 & $<0.001$ \\
\hline$>6.45 \mathrm{~cm}$ & 82 & 20 & \\
\hline \multicolumn{4}{|l|}{ Esophageal thickness } \\
\hline$\leq 1.75 \mathrm{~cm}$ & 204 & 6 & $<0.001$ \\
\hline$>1.75 \mathrm{~cm}$ & 76 & 20 & \\
\hline \multicolumn{4}{|l|}{$\begin{array}{l}\text { Extracapsular LN } \\
\text { involving esophagus }\end{array}$} \\
\hline Yes & 54 & 21 & $<0.001$ \\
\hline No & 226 & 5 & \\
\hline
\end{tabular}

(Continued)
Table 2 (Continued).

\begin{tabular}{|c|c|c|c|}
\hline \multirow[t]{2}{*}{ Variables } & $\begin{array}{l}\text { Non- } \\
\text { Perforation }\end{array}$ & Perforation & \multirow[t]{2}{*}{$P$ value } \\
\hline & $\mathbf{N}=\mathbf{2 8 0}$ & $N=26$ & \\
\hline \multicolumn{4}{|c|}{$\begin{array}{l}\text { Eccentric wall } \\
\text { thickness }\end{array}$} \\
\hline Yes & 52 & 2 & 0.164 \\
\hline No & 228 & 24 & \\
\hline \multicolumn{4}{|c|}{ Necrotic area } \\
\hline Yes & 84 & 20 & $<0.001$ \\
\hline No & 196 & 6 & \\
\hline \multicolumn{4}{|c|}{$\begin{array}{l}\text { Niche sign by } \\
\text { esophagogram before } \\
\text { RT }\end{array}$} \\
\hline Yes & 39 & 17 & $<0.001$ \\
\hline No & 241 & 9 & \\
\hline \multicolumn{4}{|l|}{ NLR } \\
\hline$\leq 2.34$ & 182 & 7 & $<0.001$ \\
\hline$>2.34$ & 98 & 19 & \\
\hline \multicolumn{4}{|l|}{ PNI } \\
\hline$\leq 47.85$ & 132 & 23 & $<0.001$ \\
\hline$>47.85$ & 148 & 3 & \\
\hline
\end{tabular}

Note: While $\mathrm{N} \geq 40$ and I 1 theoretical frequency $(T)<5$, the Fisher exact test was used to univariate analysis.

Abbreviations: BMI, body mass index; LN, lymph node; RT, radiotherapy; NLR, neutrophil to lymphocyte ratio, which was calculated by dividing the absolute neutrophil count by the absolute lymphocyte count. PNI, prognostic nutritional index, which was calculated by the serum albumin level $+5 *$ absolute lymphocyte count.

1:1 by PSM. The clinical characteristics of the two groups did not differ significantly after PSM (Table 4; Figure 3). Following PSM, the incidence of EP in the ECLNIE and non-ECLNIE groups was $21.54 \%(14 / 65)$ and $3.08 \%$ (2/ $65)$, respectively $(\mathrm{P}=0.002)$.

\section{Discussion}

EP is a serious and life-threatening side effect during and after radiotherapy in patients with ESCC. Despite a low incidence rate, EP is associated with a poor prognosis and a high mortality rate. Hence, prediction of high-risk groups before treatment is crucial for the selection of the optimal treatment method. Some recent studies have revealed some risk factors including ECLNIE for EP. However, these are mainly single-center retrospective studies that have not yet reached a consensus, and the baseline characteristics for EP in these studies are not well balanced. In this study, we comprehensively analyzed the risk factors including nutritional status, systemic inflammatory status, TNM stage, 
Table 3 Multivariate Analysis of 306 ESCC Patients

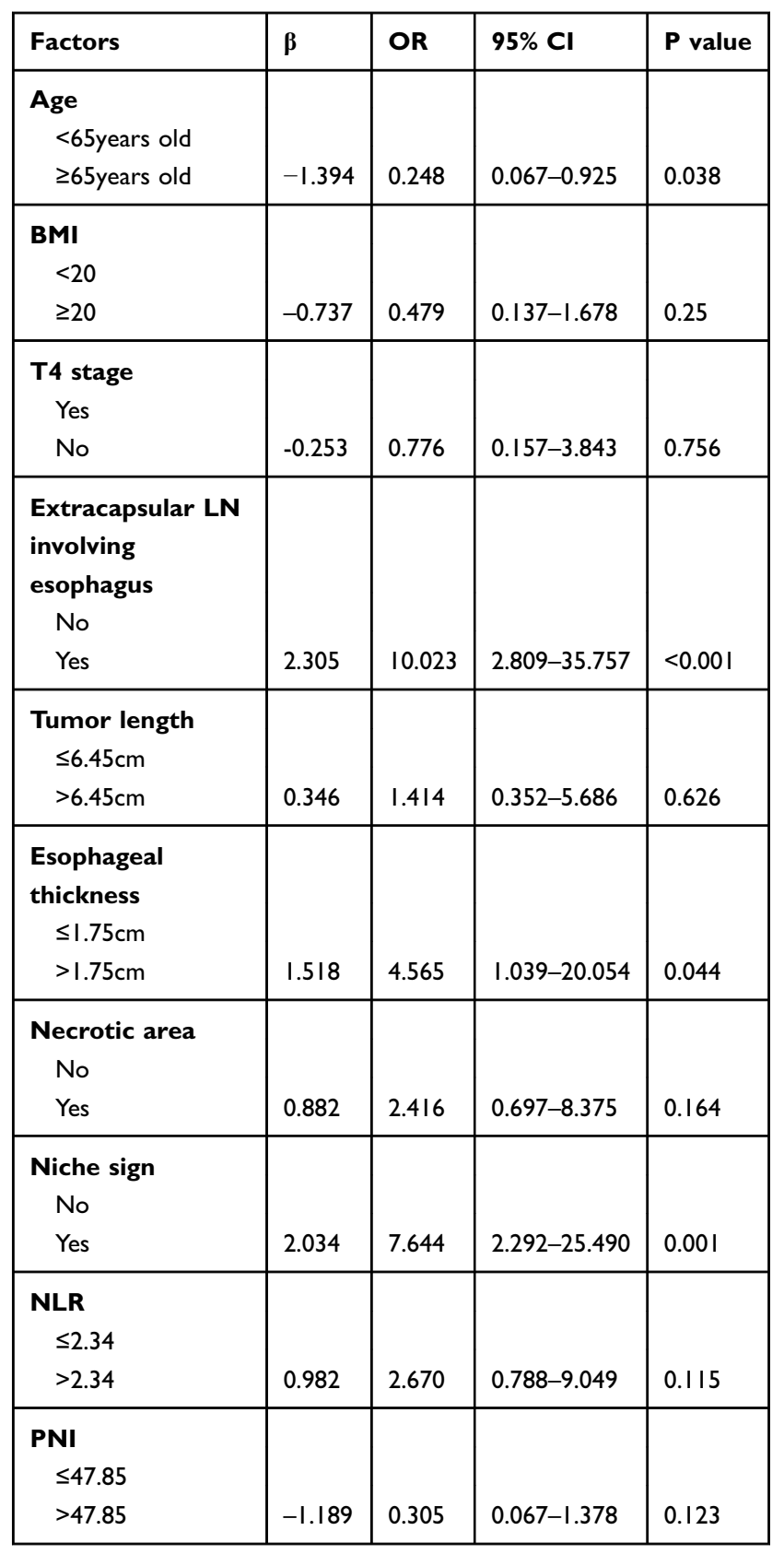

and image indicators, and performed PSM analysis to balance the baseline characteristics. We retrospectively studied 306 patients with ESCC who were treated with RT; EP was observed in 26 patients, with an incidence rate of $8.5 \%$. We observed that age, ECLNIE, esophageal wall thickness, and niche sign by esophagogram before RT were independent risk factors for EP. According to the value of $\mathrm{OR}$ in multivariable analyses before PSM, patients with ECLNIE had a higher risk for developing EP. In order to accurately assess the impact of ECLNIE, PSM was conducted to generate 65 pairs of well-matched patients. After PSM, patients with ESCC with ECLNIE had a higher risk of EP $(P=0.002)$.

ECLNIE was a negative prognostic factor for esophageal carcinoma, which had been reported in some studies. In the study by Tsushima et al, which studied 322 patients with EC, those with ECLNIE had a significantly higher risk for developing EP. Other studies also showed similar findings. ${ }^{15,16}$ The current study also showed that patients with ESCC with ECLNIE had a higher risk for developing EP. ECLNIE was treated as a risk factor mainly because the lesion had already invaded the adjacent esophageal wall structures, and the fistula was formed after necrosis of the EC and metastasis of the lymph node involving the esophageal wall. Another reason was the imbalance owing to the rapid tumor shrinkage and slow repair of normal tissue during the treatment process. Therefore, special attention should be paid to the ECLNIE, especially in the case of tumors that show a good response. Patients with ESCC with ECLNIE, especially those with rapid tumor regression, should be provided special care and should undergo regular imaging examinations including thoracic $\mathrm{CT}$ and iodine oil examination during RT in order to prevent EP.

In addition to ECLNIE, the $\mathrm{T}$ stage was reported as another risk factor for EP in some retrospective studies. Watanabe et $\mathrm{al}^{17}$ showed that 20 out of 138 patients with ESCC with stage T3-4 who received definitive CRT developed EP; however, none of the patients with ESCC stage T1-2 developed EP. Chen et $\mathrm{al}^{15}$ studied 322 patients with ESCC and demonstrated that the T4 stage was an independent risk factor for EP; patients at T4 stage showed significantly increased chances of EP. However, a study by Tsushima et $\mathrm{al}^{16}$ revealed that $\mathrm{T}$ stage was not a risk factor for EP. In our study, although the T4 stage was correlated with the development of EP, no statistical significance was observed in the multivariable analysis. However, the study revealed that esophageal thickness was an independent risk factor for EP. Thus, patients with ESCC stage T4 without thick esophageal lesions are less likely to develop esophageal fistula.

Some studies revealed that nutritional status prior to treatment had a crucial impact on the formation of EP during and after RT for EC. Poor systemic nutritional status was found to be significantly associated with the increased incidence rate of EP. A study by Watanabe et $\mathrm{al}^{17}$ on 206 patients with EC who underwent revealed that patients at ESCC stage T3 or T4 who had a low BMI $\left(<20 \mathrm{~kg} / \mathrm{m}^{2}\right)$, a well-known nutrition- 
Table 4 Clinical Characteristics of Patients Before and After Matching

\begin{tabular}{|c|c|c|c|c|c|c|c|c|}
\hline \multirow[t]{2}{*}{ Characteristic } & \multicolumn{4}{|c|}{ Umamatched Patients } & \multicolumn{4}{|c|}{ Matched Patients } \\
\hline & $\begin{array}{l}\text { ECLNIE } \\
(\mathrm{N}=75)\end{array}$ & $\begin{array}{l}\text { Non-ECLNIE } \\
(\mathrm{N}=23 \mathrm{I})\end{array}$ & $\mathbf{P}$ & $\begin{array}{l}\text { Std. } \\
\text { Diff }\end{array}$ & $\begin{array}{l}\text { ECLNIE } \\
(\mathrm{N}=65)\end{array}$ & $\begin{array}{l}\text { Non-ECLNIE } \\
(\mathrm{N}=65)\end{array}$ & $\mathbf{P}$ & $\begin{array}{l}\text { Std. } \\
\text { Diff }\end{array}$ \\
\hline $\begin{array}{l}\text { Gender } \\
\text { Male } \\
\text { Female }\end{array}$ & $\begin{array}{l}60(80 \%) \\
15(20 \%)\end{array}$ & $\begin{array}{l}172(74.46 \%) \\
59(25.54 \%)\end{array}$ & 0.33 & 0.132 & $\begin{array}{l}53(81.54 \%) \\
12(18.46 \%)\end{array}$ & $\begin{array}{l}5 \mid(78.46 \%) \\
\mid 4(2 \mid .54 \%)\end{array}$ & 0.661 & 0.077 \\
\hline $\begin{array}{l}\text { Age } \\
\qquad 65 \text { years old } \\
\geq 65 \text { years old }\end{array}$ & $\begin{array}{l}47(62.67 \%) \\
28(37.33 \%)\end{array}$ & $\begin{array}{l}104(45.02 \%) \\
127(54.98 \%)\end{array}$ & 0.008 & 0.360 & $\begin{array}{l}38(58.46 \%) \\
27(41.54 \%)\end{array}$ & $\begin{array}{l}43(66.15 \%) \\
22(33.85 \%)\end{array}$ & 0.366 & 0.159 \\
\hline $\begin{array}{l}\text { BMI } \\
\quad<20 \\
\geq 20\end{array}$ & $\begin{array}{l}28 \text { (37.33\%) } \\
47(62.67 \%)\end{array}$ & $\begin{array}{l}70(30.3 \%) \\
161(69.7)\end{array}$ & 0.257 & 0.149 & $\begin{array}{l}23(35.38 \%) \\
42(64.62 \%)\end{array}$ & $\begin{array}{l}23(35.38 \%) \\
42(64.62 \%)\end{array}$ & 1 & 0.00 \\
\hline $\begin{array}{l}\text { Smoking history } \\
\text { Yes } \\
\text { No }\end{array}$ & $\begin{array}{l}48(64 \%) \\
27(36 \%)\end{array}$ & $\begin{array}{l}140(60.6 \%) \\
91(39.4 \%)\end{array}$ & 0.6 & 0.070 & $\begin{array}{l}42(64.62 \%) \\
23(35.38 \%)\end{array}$ & $\begin{array}{l}42(64.62 \%) \\
23(35.38 \%)\end{array}$ & 1 & 0.00 \\
\hline $\begin{array}{l}\text { Alcohol consumption } \\
\text { history } \\
\text { Yes } \\
\text { No }\end{array}$ & $\begin{array}{l}18(24 \%) \\
57(76 \%)\end{array}$ & $\begin{array}{l}48(20.78 \%) \\
183(79.22 \%)\end{array}$ & 0.556 & 0.077 & $\begin{array}{l}14(21.54 \%) \\
51(78.46 \%)\end{array}$ & $\begin{array}{l}15(23.08 \%) \\
50(76.92 \%)\end{array}$ & 0.833 & 0.037 \\
\hline $\begin{array}{c}\text { T4 stage } \\
\text { Yes } \\
\text { No }\end{array}$ & $\begin{array}{l}58 \text { (77.33\%) } \\
17(22.67 \%)\end{array}$ & $\begin{array}{l}121 \text { (52.38\%) } \\
110(47.62 \%)\end{array}$ & $<0.001$ & $0.54 I$ & $\begin{array}{l}49 \text { (75.38\%) } \\
16(24.62 \%)\end{array}$ & $\begin{array}{l}52(80.0 \%) \\
13(20.0 \%)\end{array}$ & 0.527 & 0.111 \\
\hline $\begin{array}{l}\text { N stage } \\
\text { No } \\
\text { NI-3 }\end{array}$ & $\begin{array}{l}\text { I (I.33\%) } \\
74 \text { (98.67\%) }\end{array}$ & $\begin{array}{l}80(34.63 \%) \\
151(65.38 \%)\end{array}$ & $<0.001$ & 0.962 & $\begin{array}{l}\text { I ( } 1.54 \%) \\
64(98.46 \%)\end{array}$ & $\begin{array}{l}0(0.00 \%) \\
65(100.0 \%)\end{array}$ & 1 & 0.177 \\
\hline $\begin{array}{c}\text { M stage } \\
0 \\
1\end{array}$ & $\begin{array}{l}4 \mathrm{l}(54.67 \%) \\
34 \text { (45.33\%) }\end{array}$ & $\begin{array}{l}184(79.65 \%) \\
47(20.35 \%)\end{array}$ & $<0.001$ & 0.552 & $\begin{array}{l}38 \text { (58.46\%) } \\
27(41.54 \%)\end{array}$ & $\begin{array}{l}40(61.54 \%) \\
25(38.46 \%)\end{array}$ & 0.720 & 0.063 \\
\hline $\begin{array}{l}\text { Chemotherapy } \\
\text { Yes } \\
\text { No }\end{array}$ & $\begin{array}{l}64(85.33 \%) \\
\mathrm{II}(\mid 4.67 \%)\end{array}$ & $\begin{array}{l}175(75.76 \%) \\
56(24.24 \%)\end{array}$ & 0.081 & 0.244 & $\begin{array}{l}55(84.62 \%) \\
10(15.38 \%)\end{array}$ & $\begin{array}{l}55(84.62 \%) \\
10(15.38 \%)\end{array}$ & I & 0.000 \\
\hline $\begin{array}{l}\text { RT for the second time } \\
\text { Yes } \\
\text { No }\end{array}$ & $\begin{array}{l}\text { I (I.33\%) } \\
74 \text { (98.67\%) }\end{array}$ & $\begin{array}{l}10(4.33 \%) \\
221(95.67 \%)\end{array}$ & 0.226 & 0.181 & $\begin{array}{l}I(I .54 \%) \\
64(98.46 \%)\end{array}$ & $\begin{array}{l}I(I .54 \%) \\
64(98.46 \%)\end{array}$ & 1 & 0.000 \\
\hline $\begin{array}{l}\text { Tumor length } \\
\quad \leq 6.45 \mathrm{~cm} \\
>6.45 \mathrm{~cm}\end{array}$ & $\begin{array}{l}35(46.67 \%) \\
40(53.33 \%)\end{array}$ & $\begin{array}{l}169(73.16 \%) \\
62(26.84 \%)\end{array}$ & $<0.001$ & 0.562 & $\begin{array}{l}33(50.77 \%) \\
32(49.23 \%)\end{array}$ & $\begin{array}{l}36(55.38 \%) \\
29(44.62 \%)\end{array}$ & 0.598 & 0.093 \\
\hline $\begin{array}{l}\text { Esophageal thickness } \\
\begin{array}{l}\leq 1.75 \mathrm{~cm} \\
>1.75 \mathrm{~cm}\end{array}\end{array}$ & $\begin{array}{l}40 \text { (53.33\%) } \\
35 \text { (46.67\%) }\end{array}$ & $\begin{array}{l}170(73.59 \%) \\
6 \mid(26.41 \%)\end{array}$ & 0.001 & 0.430 & $\begin{array}{l}37(56.92 \%) \\
28(43.08 \%)\end{array}$ & $\begin{array}{l}34(52.31 \%) \\
31(47.69 \%)\end{array}$ & 0.597 & 0.093 \\
\hline $\begin{array}{l}\text { Eccentric wall } \\
\text { thickness } \\
\text { Yes } \\
\text { No }\end{array}$ & $\begin{array}{l}10(13.33 \%) \\
65(86.67 \%)\end{array}$ & $\begin{array}{l}44(19.05 \%) \\
187(80.95 \%)\end{array}$ & 0.259 & 0.156 & $\begin{array}{l}10(15.38 \%) \\
55(84.62 \%)\end{array}$ & $\begin{array}{l}12(18.46 \%) \\
53(81.54 \%)\end{array}$ & 0.640 & 0.082 \\
\hline
\end{tabular}

(Continued) 
Table 4 (Continued).

\begin{tabular}{|c|c|c|c|c|c|c|c|c|}
\hline \multirow[t]{2}{*}{ Characteristic } & \multicolumn{4}{|c|}{ Umamatched Patients } & \multicolumn{4}{|c|}{ Matched Patients } \\
\hline & $\begin{array}{l}\text { ECLNIE } \\
(\mathrm{N}=75)\end{array}$ & $\begin{array}{l}\text { Non-ECLNIE } \\
(\mathrm{N}=23 \mathrm{I})\end{array}$ & $\mathbf{P}$ & $\begin{array}{l}\text { Std. } \\
\text { Diff }\end{array}$ & $\begin{array}{l}\text { ECLNIE } \\
(\mathrm{N}=65)\end{array}$ & $\begin{array}{l}\text { Non-ECLNIE } \\
(\mathrm{N}=65)\end{array}$ & $\mathbf{P}$ & $\begin{array}{l}\text { Std. } \\
\text { Diff }\end{array}$ \\
\hline \multicolumn{9}{|l|}{ Necrotic area } \\
\hline Yes & $42(56.0 \%)$ & $62(26.84 \%)$ & $<0.001$ & 0.620 & 35 (53.85\%) & $29(44.62 \%)$ & 0.293 & 0.185 \\
\hline No & $33(44.0 \%)$ & $169(73.16 \%)$ & & & $30(46.15 \%)$ & $36(55.38 \%)$ & & \\
\hline \multicolumn{9}{|l|}{ Niche sign } \\
\hline Yes & 25 (33.33\%) & 31 (13.42\%) & $<0.001$ & 0.484 & $16(24.62 \%)$ & $15(23.08 \%)$ & 0.837 & 0.036 \\
\hline No & $50(66.67 \%)$ & 200 (86.58\%) & & & $49(75.38 \%)$ & $50(76.92 \%)$ & & \\
\hline \multicolumn{9}{|l|}{ NLR } \\
\hline$\leq 2.34$ & $4 \mathrm{l}(54.67 \%)$ & I 48 (64.07\%) & 0.145 & 0.192 & $36(55.38 \%)$ & $37(56.92 \%)$ & 0.860 & 0.031 \\
\hline$>2.34$ & $34(45.33 \%)$ & $83(35.93 \%)$ & & & $29(44.62 \%)$ & $28(43.08 \%)$ & & \\
\hline \multicolumn{9}{|l|}{ PNI } \\
\hline$\leq 47.85$ & $46(61.33 \%)$ & $109(47.18 \%)$ & 0.033 & 0.287 & $38(58.46 \%)$ & $34(52.31 \%)$ & 0.480 & 0.124 \\
\hline$>47.85$ & $29(38.67 \%)$ & $122(52.81 \%)$ & & & 27 (4I.54\%) & $31(47.69 \%)$ & & \\
\hline
\end{tabular}

based factor, had an increased risk of developing EP during and after RT. Another study by Singh et al ${ }^{18}$ on 52 patients with EP demonstrated that patients with lower serum albumin had higher mortality rate than that of patients with higher serum albumin, which was similar to the findings of the study by Burnett et al. ${ }^{19}$ In our study, PNI and BMI were significantly associated with EP in the univariate analysis, but they were not independent risk factors according to the multivariable analysis. Therefore, although the nutritional status of patients with ESCC affects EP, it is not the main cause of EP. Improving the nutritional status of high-risk patients could reduce the occurrence of EP.

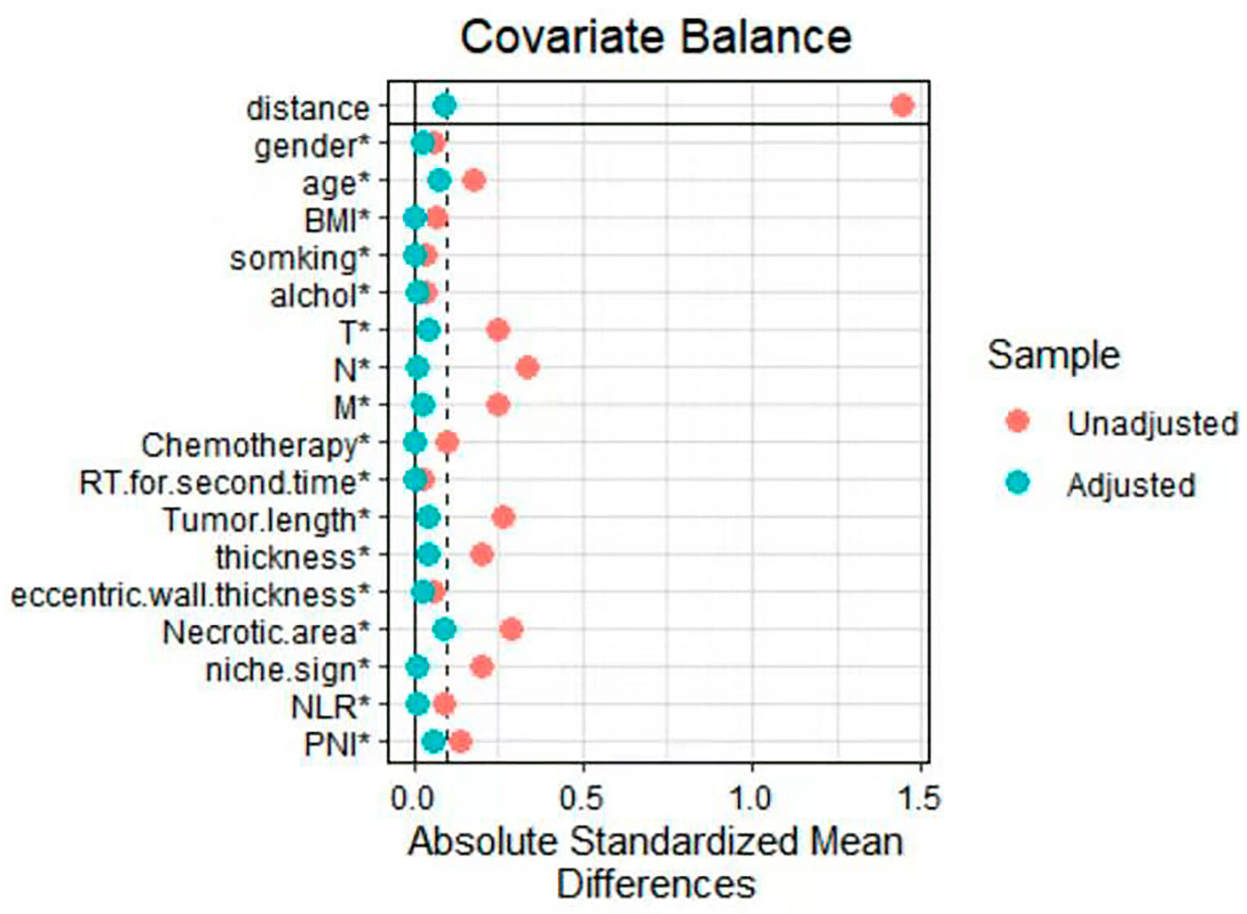

Figure 3 Dot-plot of standardized mean differences of all covariates between the pre-matched and matched groups. 
This study has some limitations. Firstly, the sample size of this study was small. A larger number of cases are required to verify the study findings. Secondly, the retrospective nature of the study reduced the overall validity of our results. Thirdly, the sample size of patients with EP was also small owing to the low incidence rate of EP. Despite the abovementioned limitations, this study was the first to conduct PSM to balance the baseline characteristics and adjust for indication biases to assess the impact of ECLNIE in EP. ECLNIE could be considered a reliable risk factor for EP to avoid EP during and after RT.

\section{Conclusion}

Overall, patients with ECLNIE have a higher risk of developing EP during and after RT. Thus, patients at a high risk of EP should be provided special attention and care, and attention should be paid to the selection of optimal treatment methods for these patients. Larger-scale studies in this regard are warranted.

\section{Abbreviations}

ESCC, esophageal squamous cell carcinoma; ECLNIE, extracapsular lymph node involving the esophagus; EP, esophageal perforation; PSM, propensity score matching; EC, esophageal cancer; IMRT, intensity-modulated radiation therapy; CT, computed tomography; BMI, body mass index; PNI, prognostic nutritional index; NLR, neutrophilto-lymphocyte ratio; $\mathrm{CI}$, confidence interval.

\section{Data Sharing Statement}

The data used to support the findings of this study are included with the article and supplementary files (Additional file 1).

\section{Ethics Approval and Consent to Participate}

This retrospective study was approved by the ethics committee of the Fujian Province Cancer Hospital and conducted in accordance with the principles of the Declaration of Helsinki and its amendment. All patients provided written informed consent prior to treatment, and all the information was anonymized prior to analysis.

\section{Acknowledgments}

The authors thank all patients who participated in the study.

\section{Author Contributions}

All authors contributed towards data analysis, drafting and critically revising the paper, gave final approval of the version to be published, and agreed to be accountable for all aspects of the work.

\section{Funding}

This study was supported in part by grants from the Fujian Provincial Platform for Medical Laboratory Research and Key Laboratory for Tumor Individualized Active Immunity (Project Number: FYKFKT-2017015).

\section{Disclosure}

The authors declare that the submitted work was not carried out in the presence of any personal, professional, or financial relationships that could potentially be construed as a conflict of interest.

\section{References}

1. Short MW, Burgers KG, Fry VT. Esophageal cancer. Am Fam Physician. 2017;95(1):22-28.

2. Huang FL, Yu SJ. Esophageal cancer: risk factors, genetic association, and treatment. Asian J Surg. 2018;41(3):210-215. doi:10.1016/j. asjsur.2016.10.005

3. Han X, Zhao YS, Fang Y, et al. Placement of transnasal drainage catheter and covered esophageal stent for the treatment of perforated esophageal carcinoma with mediastinal abscess. J Surg Oncol. 2016;114(6):725-730. doi:10.1002/jso.24384

4. Brink F, Jahne J. Current treatment and outcome of esophageal perforation in adults: systematic review and meta-analysis of 75 studies. Chirurg. 2013;84(9):799. doi:10.1007/s00104-013-2586-9

5. Marczynski W, Pajak M, Komandowska T, Nikiel I. Self-expandable metallic stents in oesophago-respiratory fistulas treatment in neoplasms - case reports and literature review. Pneumonol Alergol Pol. 2015;83(4):303-306. doi:10.5603/PiAP.2015.0050

6. Ohtsu A, Boku N, Muro K, et al. Definitive chemoradiotherapy for T4 and/or M1 lymph node squamous cell carcinoma of the esophagus. J Clin Oncol. 1999;17(9):2915-2921. doi:10.1200/ JCO.1999.17. 9.2915

7. Lagarde SM, Ten Kate FJ, de Boer DJ, Busch OR, Obertop H, van Lanschot JJ. Extracapsular lymph node involvement in node-positive patients with adenocarcinoma of the distal esophagus or gastroesophageal junction. Am J Surg Pathol. 2006;30(2):171-176. doi:10.1097/01.pas.0000189182.92815.12

8. Wind J, Lagarde SM, Ten Kate FJ, Ubbink DT, Bemelman WA, van Lanschot JJ. A systematic review on the significance of extracapsular lymph node involvement in gastrointestinal malignancies. Eur J Surg Oncol. 2007;33(4):401-408. doi:10.1016/j.ejso.2006.11.001

9. Rice TW, Ishwaran H, Ferguson MK, Blackstone EH, Goldstraw P. Cancer of the esophagus and esophagogastric junction: an eighth edition staging primer. $J$ Thorac Oncol. 2017;12(1):36-42. doi:10.1016/j.jtho.2016.10.016

10. Noh SY, Kim HJ, Lee HJ, et al. Corrosive-induced carcinoma of esophagus: esophagographic and CT findings. AJR Am J Roentgenol. 2017;208(6):1237-1243. doi:10.2214/AJR.16.17138 
11. Backer CLLC, Hartz RS. Computed tomography in patients with esophageal perforation. Chest. 1990;98:1078-1080. doi:10.1378/ chest.98.5.1078

12. Puri SK, Fan CY, Hanna E. Significance of extracapsular lymph node metastases in patients with head and neck squamous cell carcinoma. Curr Opin Otolaryngol Head Neck Surg. 2003;11(2):119-123. doi:10.1097/00020840-200304000-00010

13. Depypere LP, Moons J, Mariette C, et al. Impact of extracapsular lymph node involvement after neoadjuvant chemoradiation therapy followed by surgery in carcinoma of the esophagus: a Multicenter Study. Ann Surg. 2018;268(6):1000-1007. doi:10.1097/SLA.0000 000000002425

14. Geng $\mathrm{L}, \mathrm{Wu} \mathrm{R}, \mathrm{Hu} \mathrm{H}$, et al. Clinical application of oral meglumine diatrizoate esophagogram in screening esophageal fistula during radiotherapy for esophageal cancer. Medicine. 2018;97(18):e0668. doi:10.1097/MD.0000000000010668

15. Chen HY, Ma XM, Ye M, Hou YL, Xie HY, Bai YR. Esophageal perforation during or after conformal radiotherapy for esophageal carcinoma. J Radiat Res. 2014;55(5):940-947. doi:10.1093/jrr/rru031
16. Tsushima T, Mizusawa J, Sudo K, et al. Risk factors for esophageal fistula associated with chemoradiotherapy for locally advanced unresectable esophageal cancer: a supplementary analysis of JCOG0303. Medicine. 2016;95(20):e3699. doi:10.1097/MD.0000000000003699

17. Watanabe S, Ogino I, Kunisaki C, Hata M. Relationship between nutritional status and esophageal fistula formation after radiotherapy for esophageal cancer. Cancer Radiother. 2019. doi:10.1016/j. canrad.2018.10.005

18. Singh RK, Sahni P, Chattopadhyay TK. Esophageal perforation-the problems of late presentation. Hepatogastroenterology. 2008;55 (88):2103-2107.

19. Burnett CM, Rosemurgy AS, Pfeiffer EA. Life-threatening acute posterior mediastinitis due to esophageal perforation. Ann Thorac Surg. 1990;49(6):979-983. doi:10.1016/0003-4975(90)90882-7

\section{Publish your work in this journal}

Cancer Management and Research is an international, peer-reviewed open access journal focusing on cancer research and the optimal use of preventative and integrated treatment interventions to achieve improved outcomes, enhanced survival and quality of life for the cancer patient.
The manuscript management system is completely online and includes a very quick and fair peer-review system, which is all easy to use. Visit http://www.dovepress.com/testimonials.php to read real quotes from published authors. 